\title{
Oh Christmas Tree, Oh Christmas Tree ...
}

\section{Natalie Yanchar, Paul Pianosi, Robert Fraser}

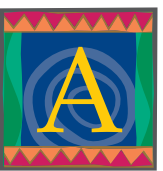

$2^{1 / 2}$-year-old boy referred to our department had a history of recurrent right lower lobe pneumonia from the age of 10 months, beginning a few months after his first Christmas. Each episode resolved with a course of antibiotics administered either intravenously or by mouth plus inhaled bronchodilators. Chest radiography revealed a persistent right lower lobe density. The boy was otherwise healthy, and his prenatal and neonatal histories were unremarkable. There was no history of choking episodes and no family history of respiratory illness.

On examination, he was a healthy-looking child. On auscultation, air entry was equal bilaterally, and there were no crackles or wheezes audible over the lungs. A CT scan of the chest revealed a nodular lesion in the lateral basal segment of the right lower lobe, with interspaced lowerattenuation regions (Fig. 1). Right hilar and subcarinal adenopathy was also visible. These findings were suggestive of an atypical pneumonia or a congenital cystic lesion of the lung, with postinflammatory changes. A CT scan of the chest repeated 4 months later showed little change. The result of a Mantoux test was negative.

Bronchoscopy was not attempted because the pathological changes revealed by CT were too peripheral and well established. The patient underwent a right thoracotomy. An inflammatory lesion densely adherent to the adjacent chest wall and affecting most of the right lower lobe was identified. A right lower lobectomy was performed without incident. The patient had an unremarkable postoperative course and was discharged home well. He has had no known recurrent bouts of pneumonia since.

The resected right lower lobe of lung weighed $173.1 \mathrm{~g}$ and measured $10 \times 9 \times 7 \mathrm{~cm}$ in maximum dimension. The pleural surface and the bronchial and vascular resection margins were unremarkable. The specimen was bisected and the lobar bronchus cut along its entire length. A foreign body measuring $3.0 \mathrm{~cm}$ in length by $0.5 \mathrm{~cm}$ in maximum diameter was embedded in the lateral basal segmental bronchus (Fig. 2). It resembled the distal branch of an evergreen tree. Microscopic pathological examination showed patchy, moderate to severe bronchopneumonia with extensive intra-alveolar hemorrhage and patchy parenchymal fibrosis. Sections from the segmental bronchus, in which the foreign body was embedded, showed a thickened bronchial wall. The wall was severely infiltrated by mixed inflammatory cells lined by an acutely inflamed epithelium, showing areas of ulceration as well as focal squamous cell metaplasia.
Recurrent pneumonia in a young child, when consistently localized to the same lung segment, should raise the suspicion of an underlying congenital or acquired disease. Pneumonia can be caused by an external compression of a
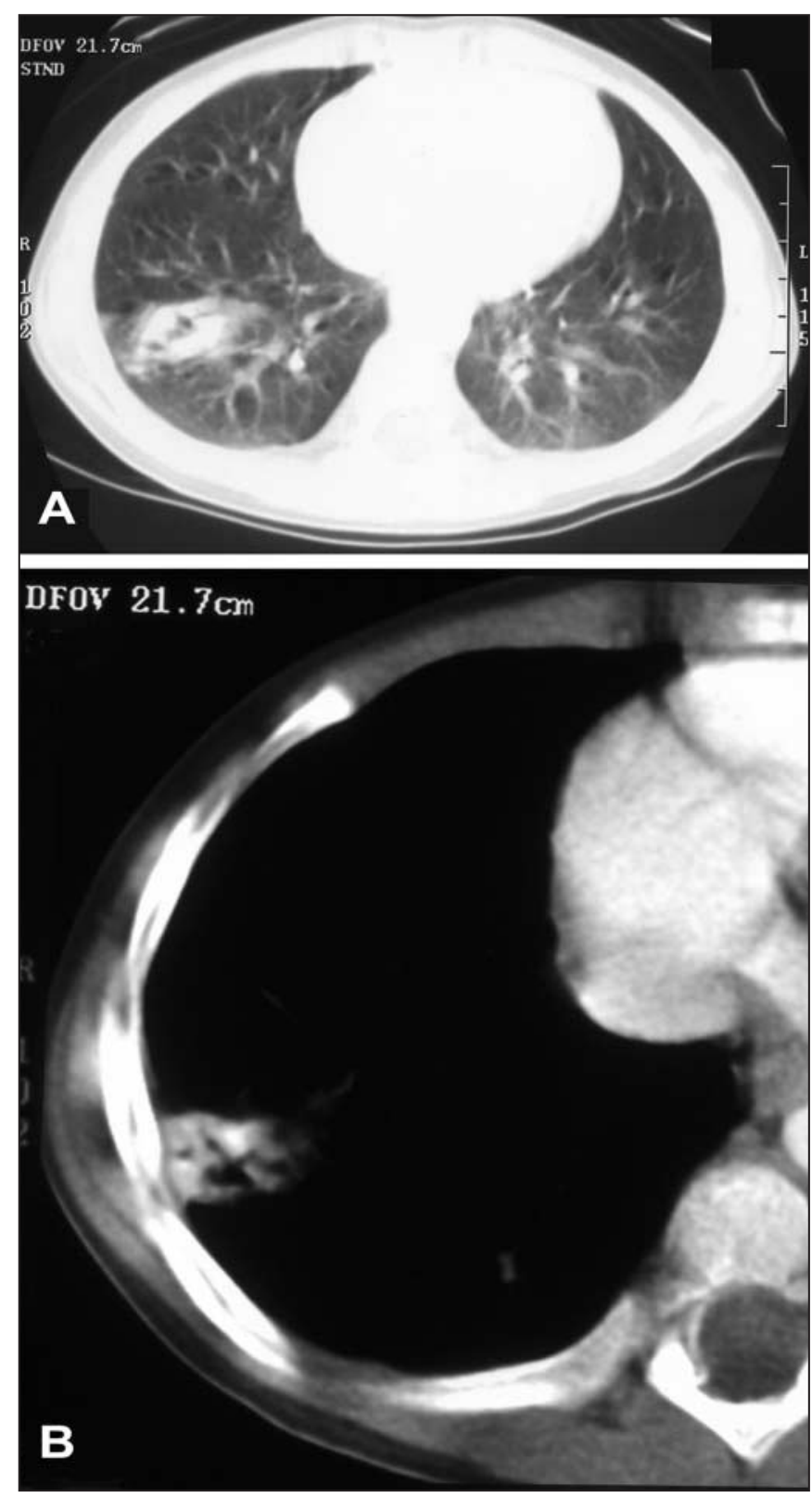

Fig. 1: CT scan of the chest showing (A) nodular density in lateral segment of right lower lobe and (B) cavitated areas with surrounding enhancement extended to the chest wall. 
bronchus by tuberculous or fungal lymphadenopathy, tumours or vascular rings. It can also result from obstruction by intraluminal lesions, such as a bronchial tumour or foreign body. ${ }^{1}$ Other conditions that may present as segmental pneumonia include localized bronchiectasis, congenital cystic adenomatoid malformations and related cystic lung pathology, such as an intralobar pulmonary sequestration. ${ }^{1}$ However, most of these lesions are detected through prenatal ultrasound screening programs. ${ }^{2,3}$

Foreign body aspiration needs to be considered in all cases of recurrent pneumonia in young children. In such cases, bronchoscopy with removal of the foreign body can be both diagnostic and therapeutic and should be the initial invasive procedure performed. ${ }^{4}$ Unless the foreign body is

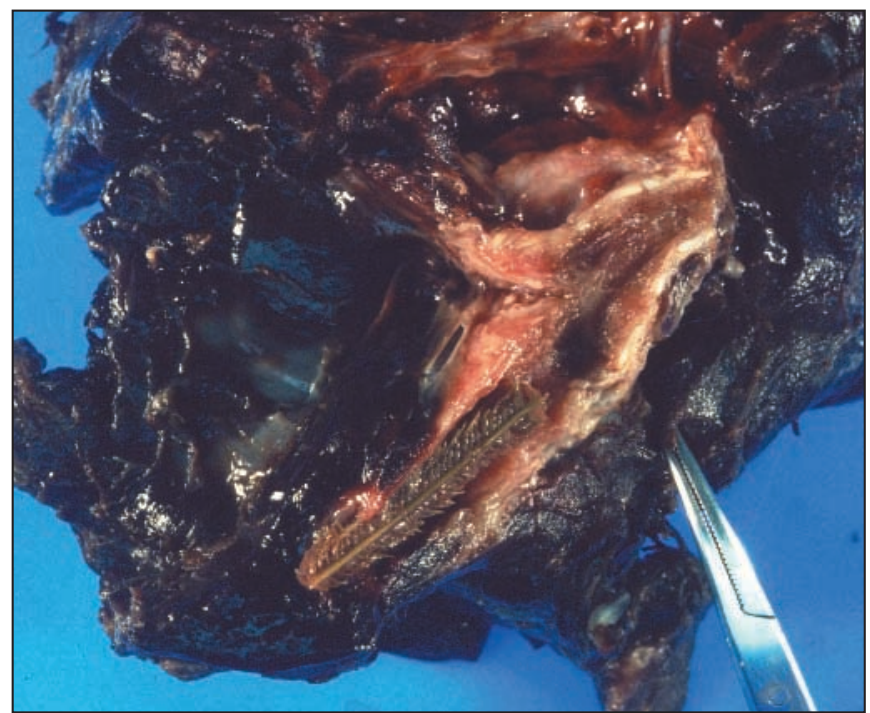

Fig. 2: Right lower lobectomy specimen. The embedded foreign body can be seen in the dissected lobar bronchus. removed, its lingering presence will trigger a persistent inflammatory response that invariably leads to recurrent symptoms and signs. In cases that are caught early, prompt resolution of the infection and inflammation can be expected after bronchoscopy, often with adjunctive antibiotic therapy. In those whose presentation is delayed, however, prolonged inflammation with dense granulated tissue in the airway may increase the difficulty of and risk of complication from the procedure. ${ }^{5}$ Finally, in long-standing cases, chronic changes may persist, and eventual resection may be necessary if intensive antibiotic therapy is not successful and associated abscesses are not drained.

The holiday season is a time for children to explore and taste new things. This is the first published case of a possible "Christmas tree aspiration" of which we are aware. We feel it merits consideration in the differential diagnosis of possible foreign body aspiration in a child shortly after the holiday season.

Natalie Yanchar is from the Division of Pediatric General Surgery, Paul Pianosi is from the Division of Respiratory Medicine and Robert Fraser is from the Division of Pathology and Laboratory Medicine, IWK Health Centre, Halifax, NS.

\section{References}

1. O'Neill JA, Grosfeld JL, Fonkalsrud EW, Coran AG, Dladamone AA. Infections of the lung and airway. In: O'Neill JA, Grosfeld JL, Fonkalsrud EW, Coran AG, Dladamone AA, editors. Principles of pediatric surgery. 2nd ed. St. Louis: Mosby; 2003. p. 349-65.

2. Davenport M, Warne SA, Cacciaguerra S, Patel S, Greenough A, Nicolaides $\mathrm{K}$. Current outcome of antenatally diagnosed cystic lung disease. 7 Pediatr Surg 2004;39(4):549-6.

3. Sauvet F, Michel JL, Benachi A, Emond S, Revillon Y. Management of asymptomatic neonatal cystic adenomatoid malformations. 7 Pediatr Surg 2003;38(94):548-52.

4. Dikensoy O, Usalan C, Filiz A. Foreign body aspiration: clinical utility of flexible bronchoscopy. Postgrad Med 7 2002;78(91):399-403.

5. Ciftci AO, Bingöl-Kologlu M, Senocak, Tanyel C, Büyükpamukçu N. Bronchoscopy for evaluation of foreign body aspiration in children. 7 Pediatr Surg 2003;38(8):1170-6. 